\title{
Esophageal Replacements for Caustic Esophageal Stenosis in Adults about 9 Cases in Ouagadougou
}

\author{
Moussa Bazongo ${ }^{*}$, Gilbert Patindé Bonkoungou1, Lamine Mohamed Sissoko", \\ Mamadou Windsouri ${ }^{1}$, Clarisse Laure Yaméogo ${ }^{1}$, Rodrigue Namékinsba Doamba ${ }^{1}$, \\ Adama Sawadogo' ${ }^{1}$, Sadio Yena ${ }^{2}$, Adama Sanou ${ }^{1}$ \\ ${ }^{1}$ Division of General and Digestive Surgery, Blaise Compaoré University Hospital, Ouagadougou, Burkina Faso \\ ${ }^{2}$ Division of Thoracic Surgery of Mali Hospital, Bamako, Mali \\ Email: ^baz_moussa@yahoo.fr
}

How to cite this paper: Bazongo, M., Bonkoungou, G.P., Sissoko, L.M., Windsouri, M., Yaméogo, C.L., Doamba, R.N., Sawadogo, A., Yena, S. and Sanou, A. (2017) Esophageal Replacements for Caustic Esophageal Stenosis in Adults about 9 Cases in Ouagadougou. Open Journal of Thoracic Surgery, 7, 46-53.

https://doi.org/10.4236/ojts.2017.73007

Received: July 31, 2017

Accepted: August 26, 2017

Published: August 29, 2017

Copyright () 2017 by authors and Scientific Research Publishing Inc. This work is licensed under the Creative Commons Attribution International License (CC BY 4.0).

http://creativecommons.org/licenses/by/4.0/

\begin{abstract}
Objective: To report our experience of the esophageal plasty for caustic stenosis of the esophagus. Methods: Retrospective study of caustic stenosis of the esophagus in patients aged over 15 years, operated in Ouagadougou from 2008 to 2016. Nine patients were operated. Patients ranged in age from 25 to 53 years. Caustic ingestion was voluntary in 6 cases. Psychiatric disorders were confirmed in one case. The type of surgery and the postoperative evolution were analyzed. Results: In 6 patients the plasty was preceded by a gastrostomy or a feeding jejunostomy. The transplant, always placed in retro sternal position, was colic in 8 cases and gastric in one case. The evolution was marked by the occurrence of a cervical fistula in 5 cases, postoperative peritonitis in 2 cases, parietal suppuration in 2 cases and pneumothorax in 3 cases. One case of death was noted. After a follow-up of 6 months to 9 years, we noted a case of dysphagia. Conclusion: Esophageal plasty is a saving gesture that restores normal nutrition to the patient. It deserves to be promoted.
\end{abstract}

\section{Keywords}

Caustic Stenosis, Esophagus, Esophagoplasty

\section{Introduction}

Adult ingestion of caustic is an uncommon and often life-threatening accident [1] [2]. Worldwide, adults represent $20 \%$ of the caustic ingestion injury population globally [3]. Attempts at autolysis account for $75 \%$ of caustic ingestions and 
are often encountered in the context of an underlying psychiatric pathology [1]. The esogastroduodenal endoscopy and esogastroduodenal transit make it possible to diagnose caustic lesions, to classify them according to their severity and extent, to assess the prognosis and to provide a therapeutic indication [2] [3]. From a therapeutic point of view, management is based on dilation and esophageal plasty. However, the results of the dilation are mediocre in the adult because of the severity of the initial lesions [4]. The esophageal plasty is effective but of last resort. Indeed, Caesar Roux, was the first one in 1907 to make an esophageal plastiy using a jejunal transplant in pre sternal at a 12 -year-old child victim of a caustic stenosis of the esophagus. This patient survived until 1947 at the age of 53 years [5]. In addition, the first use of a colonic transplant to perform the esophageal bypass was reported successively by Kelling and Vulliet in 1911 [6] [7]. Since then, esophageal replacement by a colonic transplant has become a standardized intervention with a feasibility rate close to $100 \%$ at the cost of low mortality but a relatively high specific morbidity [8]. In Burkina Faso, surgical management of caustic stenosis of the esophagus in adults is rarely practiced. We report nine cases of esophageal plasty in order to evaluate our results in order to improve the prognosis of patients with upper gastrointestinal stenosis.

\section{Patients and Methods}

This was a retrospective study of the cases of patients over 15 years of age, operated for caustic stenosis of the esophagus, between January 1, 2008 and December 31, 2016. These patients were operated at Blaise Compaoré university hospital, the SCHIPHRA Medical Center with Surgical Antenna and the New Center Clinic of Ouagadougou. The study was conducted in compliance with clinical trial legislation and approved by a national ethics committee. In 9 years, 9 patients aged 25 to 53 years were operated for dysphagia following ingestion of caustic substances. Caustic ingestion was voluntary in 6 cases and accidental in 3 cases. The average consultation period was 10 months with extremes of 3 and 24 months. Psychiatric disorders were confirmed in one case. Dysphagia and hyper sialorrhea were the main functional signs found in all patients. Two patients had unsuccessful esophageal dilation with candles. Undernutrition was noted in 6 patients. Biologically, a decrease of the protidemia, serum sodium and anemia was observed in six, five and eight patients, respectively. A high digestive fibroscopy and esogastroduodenal transit demonstrated stenosis of the esophagus in all patients. The type of surgery and the postoperative evolution were analyzed.

\section{Results}

Of our 9 patients, six benefited from the treatment of poor nutritional status preoperative by feeding gastrostomy in 3 cases and by feeding jejunostomy in 3 cases. The nutritional status of these patients was found to be satisfactory after an average duration of 7 weeks of enteral nutrition. The average delay between 
ingestion of caustic substances and esophageal plasty was 11 months. All patients were operated under general anesthesia after a previous colic preparation (administration of 4 bags of FORTRANS in 3 liters of water, orally on the eve of surgery). The approach was a median laparotomy associated with left cervicotomy in all patients. In eight patients the stomach was retracted of small size not usable. The transplant was colonic (Figure 1) in 8 cases and gastric in one case. All transplants were placed in a retro-sternal position after a strictly retrosternal tunnel was created by digitoclasia. The patients characteristics and the type of transplant used are summarized in Table 1.

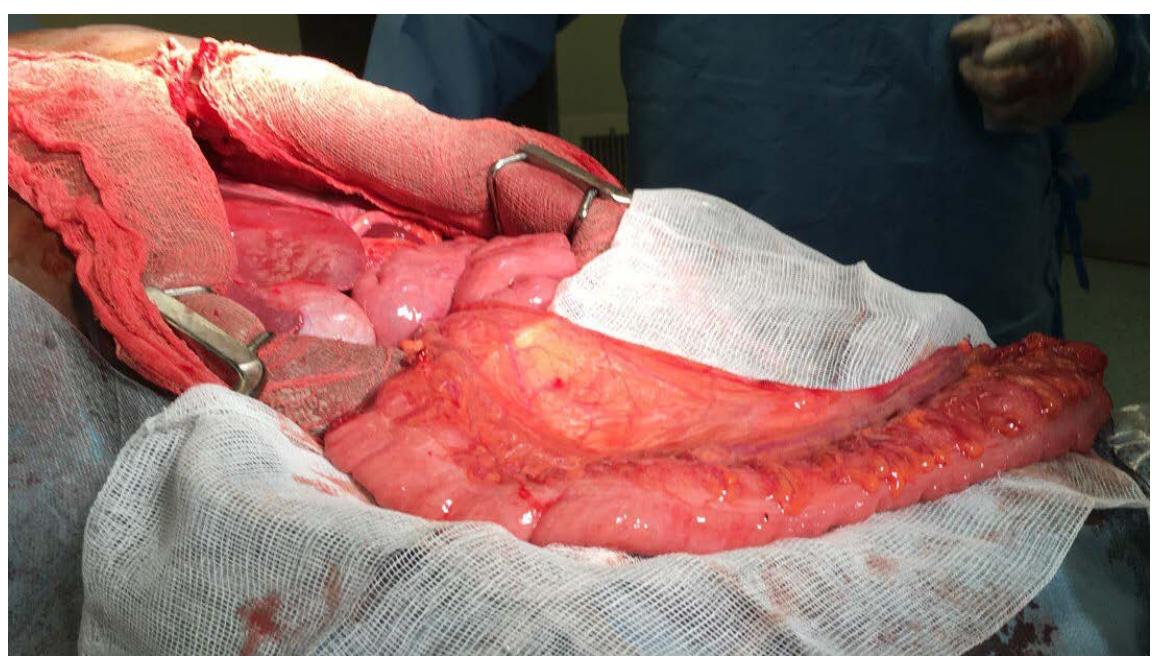

Figure 1. Intraoperative view of the transverse colic transplant pediculated on the upper right colonic artery.

Table 1. Summary table of the patients characteristics and the type of transplant.

\begin{tabular}{ccccc}
\hline Case $\begin{array}{c}\text { age (years)/ } \\
\text { sex }\end{array}$ & Function & $\begin{array}{c}\text { Nature of the caustic } \\
\text { substance }\end{array}$ & Type of transplant \\
\hline $\mathbf{1}$ & $25 / \mathrm{M}$ & Student & Sulfuric acid & $\begin{array}{c}\text { Transverse colon esophagoplasty } \\
\text { Aniso-peristaltic }\end{array}$ \\
$\mathbf{2}$ & $40 / \mathrm{M}$ & Mechanic & Sulfuric acid & $\begin{array}{c}\text { Transverse colon esophagoplasty } \\
\text { Aniso-peristaltic }\end{array}$ \\
$\mathbf{3}$ & $30 / \mathrm{W}$ & Unemployed & Caustic soda & $\begin{array}{c}\text { Transverse and left colonic esopha- } \\
\text { goplasty Iso-peristaltic }\end{array}$ \\
$\mathbf{4}$ & $36 / \mathrm{W}$ & Household & Sulfuric acid & $\begin{array}{c}\text { Transverse colonic esophagoplasty } \\
\text { Aniso-peristaltic }\end{array}$ \\
$\mathbf{5}$ & $53 / \mathrm{W}$ & Household & Sulfuric acid & $\begin{array}{c}\text { Transverse colon esophagoplasty } \\
\text { Iso-peristaltic }\end{array}$ \\
$\mathbf{6}$ & $37 / \mathrm{M}$ & Farmer & Sulfuric acid & $\begin{array}{c}\text { Right ileo-colonic esophagoplasty } \\
\text { Iso-peristaltic }\end{array}$ \\
$\mathbf{8}$ & $26 / \mathrm{M}$ & Teacher & Sulfuric acid & $\begin{array}{c}\text { Esophagoplasty by tubulistic gastritis } \\
\text { Anisoperistaltic }\end{array}$ \\
$\mathbf{9}$ & 26/M & Student & Sulfuric acid & $\begin{array}{c}\text { Transverse colon esophagoplasty } \\
\text { Aniso-peristaltic }\end{array}$ \\
\hline
\end{tabular}

M: men; W: woman. 
A jejunal probe was installed for postoperative feeding in all patients operated until resumption of oral feeding. The post-operative evolution was enamelled by complications. A pneumothorax was noted in three patients and successfully drained. Postoperative peritonitis was observed in two cases. It was due to a disunion of the colo-gastric anastomosis in one case and colo-colic in the other. The cologastric fistula was resutured. A colostomy was performed in the patient who had colocolic fistula. A daily dressing was performed in two patients who had parietal suppuration. A cervical fistula was noted in 5 cases, successfully treated with a nasogastric probe associated with a daily dressing and a diet for an average of one week. One death was recorded in the case of postoperative peritonitis due to colo-colic anastomotic disunion. With an average follow-up of $2 \frac{1 / 2}{2}$ years (extremes of 6 months to 9 years) 8 patients are alive. However, there were persistent intermittent dysphagia in one patient and the presence of depressive syndrome-like disorders in two patients.

\section{Discussion}

Esophageal plasty for caustic stenosis of the esophagus is rarely practiced in Burkina Faso; testifies our series of 9 cases carried out in 9 years in three medical centers of the city of Ouagadougou. The rarity of this intervention has been reported by several authors [9] [10] [11]. The scarcity of this surgical procedure in our country could be explained by the high cost of the procedure, which is not accessible to all the population and the inadequate technical facilities at most of our medical centers. The pneumatic dilation allow to avoid this intervention in the cases of limited stenosis which are rarely met [2]. It was practiced unsuccessfully in two cases. The last resort is esophagoplasty, which can only be performed after stabilization of the initial lesions [1] [4]. However, in diffuse esophageal necrosis (stage IIIb lesions), emergency management involves an esophagectomy, a cervical esophagostomy associated with a temporary feeding jejunostomy. A concomitant gastrectomy is frequently performed in case of necrosis of the stomach [1] [3]. In the chronic phase of caustic esophagitis, esophageal plasty is indicated in the event of failure of instrumental dilation, stenosis of more than $3 \mathrm{~cm}$ in length, multiple stenoses $(+2)$ or stenosis leading to fistula with The respiratory tract [12] [13]. The delay in consultation is frequent in our context. Also, all our patients were diagnosed with the phase of caustic stenosis of the esophagus with lesions already stabilized. The esophageal plasty was indicated after failure of a dilation with the candles in 2 cases and before impassable stenosis in 7 cases. Reconstruction of the esophagus should be postponed if the excision of the burned esophagus should be done, as the even apparently healthy pharynx may be stenosed secondarily [8]. Besides, this reconstruction varies according to the authors. In the Chien et al. experiment, this delay was less than 6 months in most patients [14], while it was 6 to 12 months in $65 \%$ of patients in the study of Knezevic et al. [4]. In our experience this period was on average 10 months. The culmination of all the cicatricial processes of the 
pharyngeal lesions and of the cervical esophagus is the main factor that determines the delay of the reconstruction [15]. Early reconstruction would expose the patient to a risk of above-anastomotic stenosis of very difficult treatment [16]. In addition, stabilization of the patient on the psychiatric plane is essential before any esophageal plasty [8]. The esophageal plasty cannot be performed in patients with a state of psychiatric instability and/or evolutive esophageal caustic lesions. The surgical approach is abdominal and cervical. At the abdominal level the median laparotomy was used in all our patients as in Reinberg [12]. However, a bi-subcostal incision should be preferred in the obese. The left cervicotomy performed in our patients has the advantage of better exposing the cervical esophagus with a lower risk of involvement of the left recurrent nerve [4]. In addition, transhiatal esophagectomy, by a laparoscopic approach would be better [12]. With regard to the transplant. The esophagus may be replaced by a colonic segment, by the whole stomach, by a gastric tube, or by the small intestine. The small intestine has been used very little because of its unfavorable vascularity and the stomach is less usable, due to the existence of lesions within it or a resection performed during the initial intervention [3] [12] [17]. However, none of these transplants reproduces perfectly the morphology and function of the esophagus [12]. The stomach, has been rarely used in our series. Our preference was the colon. The use of the colon is recommended by several authors in recent studies [6] [8]. Indeed, in the experiment of Zhou et al., in 149 patients who had an esophageal plasty, a gastric tube was used in $16.7 \%$ against a colonic plasty in 47.6\% [18]. Gastric tubes are excellent esophageal substitutes, with reliable vascularization, better than that of the colon. However, one of the major obstacles to their use is the position of the initial gastrostomy, which may be the source of gastric transplant ischemia when used in gastric tubulization [12] and also the existence of gastric lesions. The retro sternal position of the transplant is classical [4]. The pre-sternal route has been abandoned because of the aesthetic prejudices it entails [17] [19]. The assembly of the transplant in our patients was isoperistaltic in 5 cases. Most authors agree that the isoperistaltic ascent of the transplant should be favored because the anisoperistaltic ascent favors the phenomena of disabling stasis and reflux [19] [20]. Esophageal replacement surgery is a heavy surgery with a high postoperative morbidity rate as in our series. The frequency distribution of complications of esophageal plasties for caustic stenosis of the esophagus according to the studies has been summarized in Table 2.

The morbidity is a source of surgical resumption and a long duration of hospitalization which generates very important financial costs. Moreover, in our work context, The majority of the patients did not manage to honor the medicinal prescriptions. The establishment and effectiveness of universal health coverage in Burkina Faso could increase the rate of achievement and therapeutic effectiveness. The fight against ingestion of caustic substances in adults is difficult. However, the fight against social, educational and occupational stress and the 
Table 2. Distribution of the frequency of complications of esophageal plasties for caustic stenosis of the esophagus according to the studies.

\begin{tabular}{|c|c|c|c|c|c|c|c|}
\hline $\begin{array}{l}\text { 号 } \\
\text { 茕 } \\
\text { }\end{array}$ & 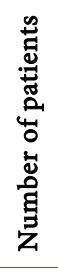 & 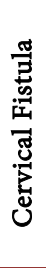 & 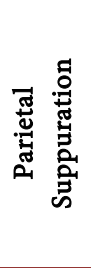 & 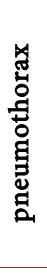 & 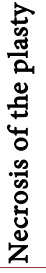 & 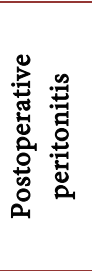 & 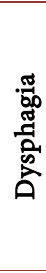 \\
\hline Knezevic et al. [4] & 336 & 30 & - & 14 & 7 & 1 & - \\
\hline Hong et al. [15] & 81 & 23 & 26 & 28 & 8 & 1 & - \\
\hline Mansour et al. [17] & 131 & 20 & - & - & 3 & - & - \\
\hline Chien et al. [14] & 60 & 6 & - & 4 & 0 & - & - \\
\hline Thomas et al. [19] & 60 & 6 & - & - & 3 & - & - \\
\hline Our series & 9 & 5 & 2 & 3 & 0 & 2 & 1 \\
\hline
\end{tabular}

effective treatment of psychiatric disorders in the population could reduce their prevalence.

\section{Conclusion}

Surgery for caustic stenosis of the esophagus in adults is rarely practiced in our country. In eight years we have collected nine cases of esophageal plasty for treatment of sequel of caustic burn. The colon was the transplant of choice used in our patients. Post-operative morbidity was cumbersome, resulting in long periods of hospitalization and significant financial costs. The functional outcome was found to be satisfactory in seven patients. Psychiatric disorders (depression + social isolation) persisted in two patients. Improving the technical platform, geographic and financial accessibility to esophageal plastic surgery could increase our efficiency results.

\section{Conflict of Interest}

The authors declare that they have no conflict Interest in relation to this article.

\section{References}

[1] Fieux, F., Chirica, M., Villa, A., Losser, M.-R. and Cattan, P. (2009) Ingestion de produits caustiques chez l'adulte. Réanimation, 18, 606-616.

https://doi.org/10.1016/j.reaurg.2009.08.003

[2] Oumnia, N., Lahcene, M., Tebaibia, A., Matougui, N., Boudjella, M.-A. and Touchene, B. (2009) Épidémiologie et évolution des brûlures caustiques du tube digestif supérieur: À propos de 483 cas. Journal Africain d'Hépato-Gastroentérologie, 3, 130-136. https://doi.org/10.1007/s12157-009-0096-7

[3] Contini, S. and Scarpignato, C. (2013) Caustic Injury of the Upper Gastrointestinal Tract: A Comprehensive Review. World Journal of Gastroenterology, 19, 3918-3930. https://doi.org/10.3748/wjg.v19.i25.3918

[4] Knežević, J., Radovanović, N.S., Simić, A.P., Kotarac, M.M., Skrobić, O.M., 
Konstantinović, V.D., et al. (2007) Colon Interposition in the Treatment of Esophageal Caustic Strictures: 40 Years of Experience. Diseases of the Esophagus, 20, 530-534. https://doi.org/10.1111/j.1442-2050.2007.00694.x

[5] Roux, C. (1907) L'oesophago-jejuno-gastrostomose: Nouvelle opération pour rétrécissement infranchissable de l'oesophage. Semaine Médicale, 27, 34-40.

[6] Kelling G. (1911) Oesophagoplastik mit Hilfeder Querkolon. Zentralbl Chirurgia, 38, 1209.

[7] Vuillet H. (1911) De l'oesophagoplastie et des diverses modifications. Semaine Médicale, (31), 529-30.

[8] Chirica, M., De Chaisemartin, C., Munoz-Bongrand, N., Halimi, B., Celerier, M., Cattan, P., et al. (2009) Reconstruction œsophagienne pour séquelles de brûlure caustique: coloplasties, mode d'emploi. Journal de Chirurgie (Paris), 146, 240-249. https://doi.org/10.1016/j.jchir.2009.06.008

[9] Odimba, E. (2002) La chirurgie de l'œsophage dans les pays en développement. Notre expérience de 15 ans. E-Mémoires de I Académie Nationale de Chirurgie, 1, 4548.

[10] Eze, J.C., Onyekwulu, F.A., Nwafor, I.A., Etukokwn, K. and Orakwe, O. (2014) Right Colon Interposition in Corrosive Esophageal Long Segment Stricture: Our Local Experience. Nigerian Journal of Clinical Practice, 17, 314-319. https://doi.org/10.4103/1119-3077.130232

[11] Rajabi, M.T., Maddah, G., Bagheri, R., Mehrabi, M., Shabahang, H. and Lorestani, F. (2015) Corrosive Injury of the Upper Gastrointestinal Tract: Review of Surgical Management and Outcome in 14 Adult Cases. Iranian Journal of Otorhinolaryngology, 27, 15-21.

[12] Reinberg, O. (2014) Les oesophagoplasties chez l'enfant. E-mémoires de I Académie Nationale de Chirurgie, 13, 11-22.

[13] Chirica, M., de Chaisemartin, C., Goasguen, N., Munoz-Bongrand, N., Zohar, S., Cattan, P., et al. (2007) Colopharyngoplasty for the Treatment of Severe Pharyngoesophageal Caustic Injuries: An Audit of 58 Patients. Annals of Surgery, 246, 721 727. https://doi.org/10.1097/SLA.0b013e3180cc2eaa

[14] Chien, K.Y., Wang, P.Y. and Lu, K.S. (1974) Esophagoplasty for Corrosive Stricutre of the Esophagus: An Analysis of 60 Cases. Annals of Surgery, 179, 510. https://doi.org/10.1097/00000658-197404000-00023

[15] Hong, P., Seel, D. and Dietrick, R. (1964) The Use of Colon in the Surgical Treatment of Benign Stricture of the Esophagus. Annals of Surgery, 160, 202-209. https://doi.org/10.1097/00000658-196408000-00006

[16] Cattan, P., Chiche, P., Berney, T., Halimi, B., Aïdan, K., Célérier, M., et al. (2001) Surgical Approach by Cervicosternolaparotomy for the Treatment of Extended Cervical Stenoses after Reconstruction for Caustic Injury. The Journal of Thoracic and Cardiovascular Surgery, 122, 384-386. https://doi.org/10.1067/mtc.2001.113740

[17] Mansour, K., Bryan, F. and Carlson, G. (1997) Bowel Interposition for Esophageal Replacement: Twenty-Five-Year Experience. The Annals of Thoracic Surgery, 64, 752-756.

[18] Zhou, J.-H., Jiang, Y.-G., Wang, R.-W., Lin, Y.-D., Gong, T.-Q., Zhao, Y.-P., et al. (2005) Management of Corrosive Esophageal Burns in 149 Cases. The Journal of Thoracic and Cardiovascular Surgery, 130, 449-455.

[19] Thomas, P., Fuentes, P., Giudicelli, R. and Reboud, E. (1997) Colon Interposition for Esophageal Replacement: Current Indications and Long-Term Function. The 
Annals of Thoracic Surgery, 64, 757-764.

[20] Kotsis, L., KrisÁr, Z., OrbanOrbÁn, K. and Csekeö, A. (2002) Late Complications of Coloesophagoplasty and Long-Term Features of Adaptation. European Journal of Cardio-Thoracic Surgery, 21, 79-83.

Submit or recommend next manuscript to SCIRP and we will provide best service for you:

Accepting pre-submission inquiries through Email, Facebook, LinkedIn, Twitter, etc. A wide selection of journals (inclusive of 9 subjects, more than 200 journals)

Providing 24-hour high-quality service

User-friendly online submission system

Fair and swift peer-review system

Efficient typesetting and proofreading procedure

Display of the result of downloads and visits, as well as the number of cited articles

Maximum dissemination of your research work

Submit your manuscript at: http://papersubmission.scirp.org/

Or contact ojts@scirp.org 